\section{Micropropagation of Oleander (Nerium oleander L.)}

\author{
Inmaculada Vila \\ Departamento de Biología Vegetal, Universidad de Valencia, Facultad de \\ Farmacia, Avda. Vicent A. Estellés s/n 46100 Burjassot, Valencia, Spain
}

\section{Ester Sales}

Departamento de Agricultura y Economía Agraria, Universidad de Zaragoza, Escuela Politécnica Superior, Ctra. Cuarte s/n 22071 Huesca, Spain

\section{Javier Ollero, Jesús Muñoz-Bertomeu, Juan Segura, and Isabel Arrillaga ${ }^{1}$ \\ Departamento de Biología Vegetal, Universidad de Valencia, Facultad de Farmacia, Avda. Vicent A. Estellés s/n 46100 Burjassot, Valencia, Spain}

Additional index words. adventitious shoots, oleander cultivars, organogenesis, ornamental shrub, shoot tips, TDZ

\begin{abstract}
Successful propagation of Nerium oleander L. (oleander) was achieved by in vitro methods. Shoot cultures were initiated from seedlings of wild-growing plants and from shoot apices of adult plants belonging to the commercial cultivars Splendens Giganteum, Revanche, and Alsace. Axillary shoot breaking from shoot tips excised from these cultures required the presence of either 6-benzylaminopurine (BA) or thidiazuron (TDZ). The higher number of axillary shoots from juvenile material was obtained by culturing shoot tips from BA-pretreated material derived from seedlings on a modified Schenk and Hildebrandt medium (SHM) supplemented with BA or TDZ (average of 3.9 shoots per explant with a mean length of $10.4 \mathrm{~mm}$ ) and when the media were supplemented with $8.8 \mu \mathrm{M}$ TDZ (average of 3.5 shoots per explant with a mean length of $7.3 \mathrm{~mm}$ ) or $4.4 \mu \mathrm{M} \mathrm{BA}$ (average of 3.3 shoots per explant with a mean length of $12.3 \mathrm{~mm}$ ). Among cultivars, cv. Revanche showed best shoot proliferation rates, especially when explants were cultured on Woody Plant Medium (average of 3.2 shoots per explant with a mean length of 10.2 $\mathrm{mm})$. Adventitious bud differentiation from oleander leaves is also reported. Leaves excised from seedling-derived shoot cultures responded better than those from adult plant-derived shoot cultures $(40 \%$ versus $5 \%$, respectively). Bud differentiation required the presence of TDZ in the SHM medium, although shoot development was only achieved on transference of explants to media without TDZ but supplemented with BA and indoleacetic acid (IAA) or BA, kinetin, and IAA. Axillary and adventitious shoots were easily rooted $(99 \%)$ and successfully $(95 \%$ to $100 \%)$ transferred to soil.
\end{abstract}

Nerium oleander L. (oleander), of the Apocynaceae family, is an evergreen shrub species native to northern Africa and the Mediterranean region widely planted as an ornamental in warm temperate and subtropical regions as a result of its abundant and longlasting flowering and its heat, salinity, and drought tolerance. Many cultivars have been selected according to the color of their simple or doubled flowers, and also completely green and variegated cultivars are produced (Huxley, 1992). Breeders are mainly interested in obtaining cultivars with new growth habits, higher resistance to pathogens (Bella et al., 2006), and improved drought and cold toler-

Received for publication 6 July 2009. Accepted for publication 21 Oct. 2009.

This research has been supported by the Generalitat Valenciana (IMPIVA-Plan Tecnológico and Conselleria de Educacion y Ciencia de la Generalitat Valenciana GV-D-VS-22-144-96, Prometeo/2009/ 075 ) and by the Spanish Government (Ministerio de Educación y Ciencia BIO97-0578-C03-03).

${ }^{1}$ To whom reprint requests should be addressed; e-mail isabel.arrillaga@uv.es. ance (Mackay et al., 2005; Niu et al., 2008). Cultivars are clonally propagated by cuttings (Hartmann et al., 2002), but also tissue culture techniques have been described: Jacquemont et al. (1992) reported on axillary proliferation of 'Petite Salmon', a dwarf cultivar; Pal et al. (1990) induced root organogenesis from leafderived calli but failed to induce shoot organogenesis; Santos et al. (1994) reported on somatic embryogenesis from oleander leaf explants, whereas more recently, OzdenTokatli et al. (2008) have referred a protocol for the medium-term conservation of oleander buds in synthetic seeds. In vitro propagation of ornamental plants allows the high rate and continuous production of clones and can also be used to clean up plant material affected by some pathology such as for oleander plants can be leaf scorch, caused by Xylella fastidiosa subsp. sandyi, and leaf blight, caused by Pseudomonas savastanoii pv. nerii (Phelan et al., 2009, and references therein).

In addition to its value as a garden plant, oleander is economically important for the pharmaceutical industry because it produces bioactive secondary metabolites, mainly car- denolides, flavonoids, and terpenes (Fu et al., 2005; Zhao et al., 2007). For example, oleandrin has been identified as a potent antitumor compound (Manna et al., 2000). Given the commercial value of oleander metabolites, their production by plant cell cultures has been also the subject of study (Ibrahim et al., 2007, 2009; Paper and Franz, 1993; Profumo et al., 1993). Finally, Nerium oleander can be used for wastewater purification and for restoration of riparian woodlands (Adrover et al., 2008).

Besides the interest of oleander micropropagation for commercial-scale plant production, adventitious regeneration would allow the genetic engineering of this plant species, and therefore oleander plants with new favorable traits such as herbicide tolerance, reduced height, pathogen resistance, and engineered metabolites could be obtained. To date, however, there is only one reference on the genetic transformation of oleander callus by a wild strain of Agrobacterium tumefaciens from which cell cultures were derived for oleandrin production (Ibrahim et al., 2007). Transgenic oleander plants have not yet been reported, probably as a result of the limited information about morphogenesis on this species. The aim of this research was to develop methods for the in vitro clonal propagation of Nerium oleander. Factors controlling both axillary shoot proliferation and adventitious shoot differentiation, a morphogenic response not previously reported for this plant species, are presented.

\section{Materials and Methods}

Plant material and culture conditions. Explants used in the regeneration experiments were taken from juvenile (seedlings and seedling-derived cultures from oleander) and from adult plants of three commercial cultivars: 'Splendens Giganteum' with double dark rose flowers, 'Revanche' with red semidouble flowers, and 'Alsace' with simple white flowers. These cultivars were kindly provided by the Asociación Profesional de Flores, Plantas y Tecnología Hortícola de la Comunidad Valenciana (Valencia, Spain).

To obtain juvenile plant material, random bulk seeds were collected from oleander plants growing in their natural habitat (Valle de la Gallinera, Alicante, Spain) and sterilized by immersion in a $25 \%$ solution of commercial bleach for $15 \mathrm{~min}\left(50 \mathrm{~g} \cdot \mathrm{L}^{-1}\right.$ of active chloride) followed by three rinses in distilled sterile water. Seeds were then germinated in test tubes $(25 \times 15 \mathrm{~mm})$ covered with polypropylene closures (Wellco, Vineland, NJ) containing $20 \mathrm{~mL}$ of basal medium (BM) consisting of Murashige and Skoog (MS) major and minor salts (Murashige and Skoog, 1962), B5 vitamins (Gamborg et al., 1968), and $3.0 \%$ sucrose. The $\mathrm{pH}$ was adjusted to 5.8 and the medium was solidified with $0.7 \%$ agar (Agar industrial; Pronadisa, Hispanlab, S.A., Alcobendas, Madrid, Spain) before being autoclaved for $20 \mathrm{~min}$ at $120{ }^{\circ} \mathrm{C}$. Seedling-derived cultures were maintained by transferring shoot apices to $250-\mathrm{mL}$ glass 
vessels containing $40 \mathrm{~mL} B M$ with the ammonium nitrate salt reduced to half of its original concentration (BMN/2) and $4.4 \mu \mathrm{M}$ 6-benzylaminopurine (BA) (hereafter referred to as maintenance medium). Vessels were covered with sun cap transparent film closures (Sigma Chemical Co., St. Louis, MO). Every 3 weeks, individual shoot apices and nodal segments were excised and transferred to the same fresh medium. Shoot tips and leaves from these proliferating cultures were further used as explants.

Adult plant material was obtained from leafless lateral cuttings (10 $\mathrm{cm}$ in length) cultured in pots containing $2 \mathrm{~mL} \cdot \mathrm{L}^{-1}$ Pelt $\AA$ (a systemic fungicide that contains $45 \%$ of methyl thiophanate; Bayer CropScience, Valencia, Spain) aqueous solution. To encourage bud growth, cuttings were sprayed with $44.4 \mu \mathrm{M}$ BA and kept in a growth chamber ( $75 \%$ relative humidity, $28 \pm 1{ }^{\circ} \mathrm{C}$, and a $16-\mathrm{h}$ photoperiod of $80 \mu \mathrm{mol} \cdot \mathrm{m}^{-2} \cdot \mathrm{s}^{-1}$ irradiance at culture level). Emerging sprouts $(1 \mathrm{~cm})$ were collected after $15 \mathrm{~d}$, rinsed for $12 \mathrm{~h}$ in running tap water, and surface-sterilized by sequential immersion in $10 \%$ Mercryl-laurile (a medical disinfectant composed of $0.1 \mathrm{~g} \cdot \mathrm{L}^{-1}$ mercurobutol and $40.8 \mathrm{~g} \cdot \mathrm{L}^{-1}$ sodium lauryl sulphate; Labaz S.A., Gerona, Spain) for $30 \mathrm{~min}$, and $3 \% \mathrm{NaOCl}$ for $15 \mathrm{~min}$. After four 5-min washes with sterile distilled water, shoot apices were excised, transferred to the maintenance medium, and kept in proliferation by sequential subcultures as described for seedlingderived shoots.

Unless otherwise specified, cultures were kept in growth chambers at $25 \pm 2{ }^{\circ} \mathrm{C}$ and a 16-h photoperiod provided by Sylvania (GTE gro-lux; F36W/GRO, Erlangen, Germany) cool-white fluorescent tubes $\left(60 \mu \mathrm{mol} \cdot \mathrm{m}^{-2} \cdot \mathrm{s}^{-1}\right.$ irradiance at culture level).

Axillary shoot proliferation. Apical shoottips ( 1 to $2 \mathrm{~mm}$ in length) from both seedlings (15-d-old) and previously established shoot cultures of seedlings and adult plants (6week-old) were individually transferred to test tubes containing $20 \mathrm{~mL}$ of proliferation media. Four proliferation media were tested and contained either the MS major salts (BM), the MS major salts with the ammonium reduced to a half (BMN/2), the Schenk and Hildebrandt (1972) major salts (SHM) or the Woody Plant Medium (WPM) major salts (Lloyd and McCown, 1980). Media also contained MS minor salts, B5 vitamins, 3\% sucrose, and $0.7 \%$ agar and were supplemented with 0 , 4.4 , or $8.8 \mu \mathrm{M}$ of BA or thidiazuron (TDZ) in a factorial design. Twelve explants from each origin and cultivar were prepared for each treatment. After $45 \mathrm{~d}$, data on number of shoots per explant and shoot elongation (mean length of the highest shoot, in millimeters) were recorded. Experiments were conducted twice.

Adventitious shoot differentiation. In a preliminary experiment, leaf explants $(1 \times$ $0.4 \mathrm{~cm}$ ) excised from 3-week-old in vitrogrown shoots (derived from both seedlings and adult plants) were cultured in petri dishes $(9 \mathrm{~cm} \varnothing)$ containing $20 \mathrm{~mL}$ of either SHM or WPM with the following growth regulator treatments: TDZ $(4.4$ or $8.8 \mu \mathrm{M})$ alone or with indoleacetic acid (IAA; 2.2 or $4.4 \mu \mathrm{M}$ ), and combinations of TDZ/BA/IAA or BA/ kinetin/IAA at different micromolar concentrations each (13.2/13.2/4.4 and 8.8/8.8/4.4). Each treatment contained 12 replicates (12 dishes with five explants each) and culture time was $30 \mathrm{~d}$.

On the basis of this experiment, leaf explants from 3-week-old in vitro-grown shoots (derived from both seedlings and adult plants) were first cultured for 15 or $30 \mathrm{~d}$ on SHM with $4.4 \mu \mathrm{M}$ TDZ and $2.2 \mu \mathrm{M}$ IAA (hereafter referred as to induction medium) and then transferred to the same medium with the following growth regulator combinations: $4.4 \mu \mathrm{M}$ BA and $2.2 \mu \mathrm{M}$ IAA; $4.4 \mu \mathrm{M}$ BA, 4.4 $\mu \mathrm{M}$ kinetin (Kin), and $2.2 \mu \mathrm{M}$ IAA; and 2.2 $\mu \mathrm{M}$ BA, $2.2 \mu \mathrm{M}$ Kin, and $0.4 \mu \mathrm{M}$ IAA. A complete random design was used. An induction medium containing $8.8 \mu \mathrm{M}$ TDZ and $2.2 \mu \mathrm{M}$ IAA was also tested for explants from seedling-derived shoots. Each treatment contained five replicates (five dishes with five explants each) and culture time was $60 \mathrm{~d}$.

In all experiments, cultures were maintained for $15 \mathrm{~d}$ in the dark and then transferred to photoperiodic conditions. Cultures were examined for percent of explants with shoots and the number of adventitious shoots per explant.

Rooting and acclimatization. Both axillary and adventitious shoots longer than $1 \mathrm{~cm}$ were isolated from proliferating cultures and individually transferred to test tubes containing half-strength BM with or without $0.5 \mu \mathrm{M}$ indole-butyric acid (IBA). At least 24 shoots for each origin (wild plants or the three commercial cultivars) and rooting treatment were used. Rooting percentages were recorded after $30 \mathrm{~d}$. Rooted shoots were transplanted to $100-\mathrm{mL}$ pots containing a mixture of 1:1 perlite:peatmoss and adapted to growth chamber conditions $(75 \%$ relative humidity, $28 \pm 1{ }^{\circ} \mathrm{C}$, and a $16-\mathrm{h}$ photoperiod of 80 $\mu \mathrm{mol} \cdot \mathrm{m}^{-2} \cdot \mathrm{s}^{-1}$ irradiance at culture level) with gradual exposure to reduced relative humidity by progressively removing a transparent plastic cover during 2 to 3 weeks. Once acclimatization was accomplished, plants were transferred to the greenhouse and transplanted to $10-\mathrm{L}$ pots containing the same substrate. Drip irrigation provided moisture for maintenance of vigorous growth. Pots were regularly surface irrigated with half-strength Hoagland and Arnon (1950) nutrient solution.

Statistical analysis. Significance of treatment effects was determined by analysis of variance (ANOVA). When responses did not change through treatments, the corresponding data were omitted from the ANOVA (Mize et al., 1999). Percentage data were subjected to arcsine transformation before statistical analysis. Variation among treatments means was analyzed using Tukey's (1953) procedure.

\section{Results and Discussion}

\section{Axillary shoot proliferation}

Shoot tips from either seedlings or adult material cultured on media without growth regulators elongated and produced only one shoot, whereas axillary branching required the presence of cytokinins in the culture medium (Fig. 1A).

For seedling-derived material, significant differences were found among media for the percentage of explants with more than one shoot (ANOVA data not shown) with SHM and WPM being superior to $\mathrm{BM}$ and $\mathrm{BMN} / 2$ $(81.2 \%$ and $78.1 \%$ versus $69.8 \%$ and $60.4 \%$, respectively; $P \leq 0.05$ ). BA was also more effective for axillary bud breaking than TDZ $(82.3 \%$ versus $62.5 \%$, respectively; $P \leq$ 0.05); furthermore, $\mathrm{BM}$ with $8.8 \mu \mathrm{M}$ TDZ drastically reduced the sprouting percentage from seedling shoot tips (25\%). Branching on BA-supplemented media occurred without callus formation. In contrast, addition of TDZ induced a basal compact green nodular callus mainly in SHM or WPM media, a response already reported for other species (Debnath, 2005; Murthy et al., 1998). Occasionally, these calli developed shoot-like structures that did not elongate when transferred to hormone-free medium.

The number of shoots formed per explant depended on shoot tip origin, culture medium, and cytokinin type (Table 1). Explants isolated from in vitro-grown shoots (BApretreated) produced on average higher shoot proliferation rates ( 2.9 versus $2.4 ; P \leq 0.05$ ). A significant interaction between shoot tip origin and culture medium showed that in vitro-grown shoot tips reached higher shoot proliferation rates when cultured on SHM (Table 1), especially when this medium was supplemented with TDZ (average of 4.6 shoots per explant with a mean length of 6.9 $\mathrm{mm})$. ANOVA also demonstrated a significant interaction among shoot tip origin, cytokinin type, and cytokinin level (Table 1); thus, cytokinin concentrations did not significantly affect axillary branching in seedling-derived explants, whereas shoot tips isolated from shoots cultured in the presence of BA showed the highest proliferation rates on media with $8.8 \mu \mathrm{M}$ TDZ or $4.4 \mu \mathrm{M}$ BA (average of 3.5 and 3.3 shoots per explant with a mean length of 7.3 and $12.4 \mathrm{~mm}$, respectively). Neither culture medium nor cytokinin type or level affected shoot length on shoot tips excised from seedlings; WPM however favored shoot elongation on in vitro-grown shoots cultured in the presence of $4.4 \mu \mathrm{M}$ TDZ (mean shoot length $21.7 \mathrm{~mm}$ ).

\section{Axillary shoot proliferation from commercial plant material}

After $30 \mathrm{~d}$, the percentage of cultures exhibiting axillary shoot growth ranged from $25 \%$ to $100 \%$. The frequency of explants forming shoots was significantly higher (ANOVA data not shown) on SHM and WPM than on BMN/2 or BM (averages of $70.1 \%$ and $71.5 \%$ versus $57.6 \%$ and $48.6 \%$, respectively; $P \leq 0.01$ ) and strongly depended on the cultivar (average of $70.3 \%$, $62.5 \%$, and $53.1 \%$ for 'Revanche', 'Alsace', and 'Splendens Giganteum', respectively; $P \leq 0.01)$. This analysis also enlightens significant double and triple interactions 

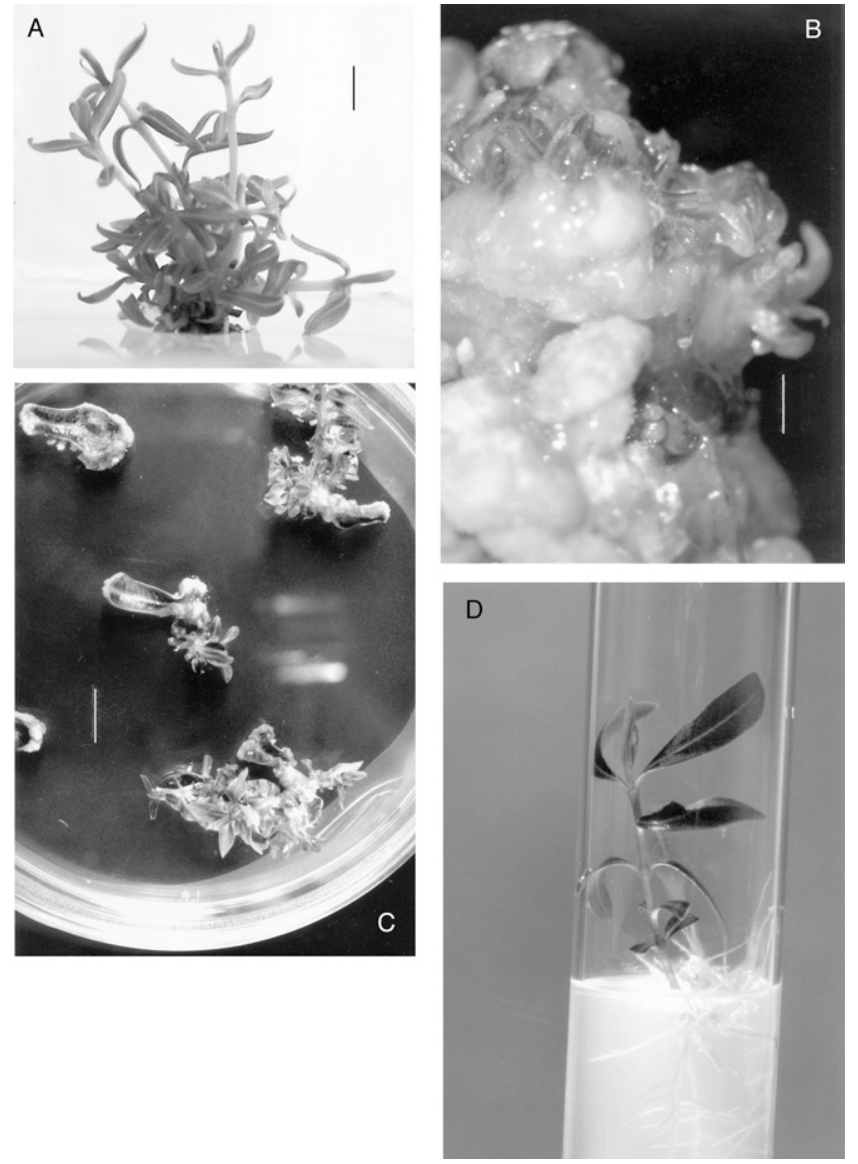

Fig. 1. Micropropagation of oleander. (A) Axillary shoot proliferation on Woody Plant Medium supplemented with $4.4 \mu \mathrm{M}$ 6-benzylaminopurine (BA) of a shoot tip excised from shoot cultures of oleander 'Revanche'. Culture time was 5 weeks. Bar $=4 \mathrm{~mm}$. (B) Adventitious shoots and nodular callus from oleander 'Alsace' leaf explants cultured on Schenk and Hildebrandt medium (SHM) supplemented with $4.4 \mu \mathrm{M}$ thidiazuron (TDZ). Culture time was 4 weeks. Bar $=0.6 \mathrm{~mm}$. (C) Adventitious shoot development from oleander leaf explants, excised from seedling-derived shoot cultures, after $30 \mathrm{~d}$ on SHM with $8.8 \mu \mathrm{M}$ TDZ and $2.2 \mu \mathrm{M}$ indoleacetic acid (IAA) and $30 \mathrm{~d}$ on BA/ kinetin/IAA 4.4/4.4/2.2 $\mu \mathrm{M}$. Bar $=6 \mathrm{~mm}$. (D) In vitro rooting of an oleander shoot from 'Revanche' on $\mathrm{BM} / 2$ without growth regulators. Culture time was 1 month.

Table 1. Effect of explant origin, culture medium, and cytokinin treatment on mean shoot number per explant from shoot tip cultures of juvenile oleander. ${ }^{2}$

\begin{tabular}{|c|c|c|c|c|c|c|c|}
\hline \multirow[b]{2}{*}{ Shoot tip origin $y$} & \multicolumn{2}{|c|}{ Cytokinin $(\mu \mathrm{M})^{\mathrm{x}}$} & \multicolumn{5}{|c|}{ Culture medium } \\
\hline & TDZ & $\overline{\mathrm{BA}}$ & BM & $\mathrm{BMN} / 2$ & SHM & WPM & Mean $^{v}$ \\
\hline \multirow[t]{6}{*}{ Seedlings } & 0.0 & 0.0 & 1.0 & 1.0 & 1.0 & 1.0 & \\
\hline & 4.4 & 0.0 & $2.3 \pm 0.3$ & $1.6 \pm 0.3$ & $2.3 \pm 0.4$ & $1.7 \pm 0.3$ & $2.0 \mathrm{~d}$ \\
\hline & 8.8 & 0.0 & $1.3 \pm 0.2$ & $1.6 \pm 0.3$ & $2.4 \pm 0.3$ & $2.3 \pm 0.3$ & $1.9 \mathrm{~d}$ \\
\hline & 0.0 & 4.4 & $2.4 \pm 0.2$ & $2.7 \pm 0.3$ & $2.7 \pm 0.2$ & $2.1 \pm 0.3$ & $2.5 \mathrm{bcd}$ \\
\hline & 0.0 & 8.8 & $3.7 \pm 0.4$ & $2.9 \pm 0.2$ & $2.7 \pm 0.2$ & $2.9 \pm 0.3$ & $3.0 \mathrm{abc}$ \\
\hline & \multicolumn{2}{|c|}{ Mean $^{w}$} & $2.4 \mathrm{bc}$ & $2.2 \mathrm{c}$ & $2.5 \mathrm{bc}$ & $2.3 \mathrm{bc}$ & \\
\hline \multirow{6}{*}{$\begin{array}{l}\text { In vitro-grown } \\
\text { shoots }\end{array}$} & 0.0 & 0.0 & 1.0 & 1.0 & 1.0 & 1.0 & \\
\hline & 4.4 & 0.0 & $1.5 \pm 0.2$ & $1.8 \pm 0.3$ & $3.9 \pm 0.5$ & $2.7 \pm 0.4$ & $2.5 \mathrm{bcd}$ \\
\hline & 8.8 & 0.0 & $2.8 \pm 0.3$ & $1.9 \pm 0.3$ & $5.2 \pm 1.9$ & $4.2 \pm 0.6$ & $3.5 \mathrm{a}$ \\
\hline & 0.0 & 4.4 & $3.8 \pm 0.3$ & $2.7 \pm 0.5$ & $4.0 \pm 0.4$ & $2.8 \pm 0.4$ & $3.3 \mathrm{ab}$ \\
\hline & 0.0 & 8.8 & $2.2 \pm 0.3$ & $2.1 \pm 0.2$ & $2.4 \pm 0.3$ & $2.6 \pm 0.3$ & $2.3 \mathrm{~cd}$ \\
\hline & \multicolumn{2}{|c|}{ Mean $^{w}$} & $2.6 \mathrm{bc}$ & $2.1 \mathrm{c}$ & $3.9 \mathrm{a}$ & $3.1 \mathrm{~b}$ & \\
\hline
\end{tabular}

${ }^{\mathrm{x}}$ Data are means $\pm \mathrm{SE}$ of 12 replications after $45 \mathrm{~d}$ of culture.

${ }^{y}$ Shoot tips were isolated from seedlings or from shoots grown in vitro on BA-supplemented medium (maintenance medium).

${ }^{\mathrm{x}}$ Treatments without growth regulators were omitted from the analysis.

winteraction between shoot tip origin and culture medium. Values followed by the same letter are not significantly different according to the Tukey's test $(P \leq 0.05)$.

'Interaction among shoot origin, cytokinin type, and cytokinin level. Values followed by the same letter are not significantly different according to the Tukey's test $(P \leq 0.05)$.

$\mathrm{TDZ}=$ thidiazuron; $\mathrm{BA}=6$-benzylaminopurine; $\mathrm{BM}=$ basal medium; $\mathrm{BMN} / 2=\mathrm{BM}$ with the ammonium nitrate salt reduced to a half of its original concentration; $\mathrm{SHM}=$ Schenk and Hildebrandt medium; WPM = Woody Plant Medium. among cultivar and cytokinin level with either media or cytokinin type. The ANOVA for the mean number of shoots formed per explant, after $45 \mathrm{~d}$, also showed the effect of the cultivar with 'Revanche' producing a higher $(P \leq 0.05)$ number of shoots (an average of 2.6 shoots per explant) than 'Alsace' and 'Splendens Giganteum' (an average of 2.1 and 2.0 shoots per explant, respectively). A significant full interaction among all factors was also evident. To gain a better interpretation of these results, individual ANOVA for each cultivar was performed, detailed subsequently (Table 2).

Splendens Giganteum cultivar. None of the main factors tested significantly affected shoot proliferation. Note, however, that significant interactions between culture media and cytokinin level or cytokinin type and level were evident. Thus, the highest cytokinin level $(8.8 \mu \mathrm{M})$ significantly reduced shoot proliferation when added to BMN/2 (2.3 versus 1.4 shoots per explant). Furthermore, irrespective of the culture medium, TDZ was more effective at $4.4 \mu \mathrm{M}$, whereas no differences were observed between the two BA concentrations tested. Shoot length ranged from 2.0 to $8.5 \mathrm{~mm}$, with shoot elongation favored by the addition of cytokinins, although the effect was highly variable and depended on nutrient medium and cytokinin level (data not shown). For this cultivar, the preferred micropropagation protocol includes WPM medium supplemented with $8.8 \mu \mathrm{MBA}$ that provides a mean of 3.0 shoots per explant with an average length of $5.7 \mathrm{~mm}$.

Revanche cultivar. Shoot proliferation depended on culture medium, WPM and SHM showing superior results as compared with $\mathrm{BM}$ and $\mathrm{BMN} / 2$, particularly when 4.4 or $8.8 \mu \mathrm{M}$ TDZ was added to BM or $8.8 \mu \mathrm{M}$ TDZ to BMN/2 (Table 2). Maximal shoot proliferation was obtained by adding $4.4 \mu \mathrm{M}$ of either cytokinin to WPM (3.5 to 3.7 shoots/ explant; Table 2). ANOVA demonstrated a significant effect of the nutrient media as well as a significant interaction among all factors tested. Shoot length was again highly variable, ranging from 1 to $45 \mathrm{~mm}$, and was affected by all the factors tested. Higher shoot elongation was obtained when shoot tips were cultured on SHM with TDZ, whereas shoot tips cultured on SHM or WPM without growth regulators did not elongate (data not shown). The preferred protocol to propagate this cultivar includes WPM with $4.4 \mu \mathrm{M}$ TDZ that provides a mean of 3.5 shoots per explant with an average length of $25.2 \mathrm{~mm}$.

Alsace cultivar. As already reported for the other cultivars, axillary shoot proliferation was favored on SHM or WPM. In addition, a significant interaction between cytokinin type and level was observed. Thus, axillary branching was not significantly affected by TDZ concentrations, whereas $4.4 \mu \mathrm{M}$ BA reduced the mean number of formed shoots per explant (Table 2). Shoot length ranged from 3.8 to $12.7 \mathrm{~mm}$. The presence of cytokinins favored shoot elongation, especially on either BM or BMN/2 media, in which a twofold increase was recorded (data not shown). 
Table 2. Effect of culture medium and cytokinins on mean shoot number per explant from shoot tip cultures established from adult plants of three oleander cultivars. ${ }^{z}$

\begin{tabular}{|c|c|c|c|c|c|c|c|}
\hline \multirow[b]{2}{*}{ Cultivar ${ }^{\mathrm{y}}$} & \multicolumn{2}{|c|}{ Cytokinin $(\mu \mathrm{M})^{\mathrm{x}}$} & \multicolumn{5}{|c|}{ Culture medium } \\
\hline & TDZ & $\mathrm{BA}$ & $\mathrm{BM}$ & $\mathrm{BMN} / 2$ & SHM & WPM & $\overline{\text { Mean }^{v}}$ \\
\hline Splendens & 0.0 & 0.0 & 1.0 & 1.0 & 1.0 & 1.0 & \\
\hline \multirow[t]{5}{*}{ Giganteum } & 4.4 & 0.0 & $2.3 \pm 0.3$ & $2.6 \pm 0.3$ & $2.8 \pm 0.3$ & $1.9 \pm 0.3$ & $2.4 \mathrm{a}$ \\
\hline & 8.8 & 0.0 & $1.5 \pm 0.2$ & $1.2 \pm 0.1$ & $1.7 \pm 0.2$ & $1.7 \pm 0.3$ & $1.6 \mathrm{c}$ \\
\hline & 0.0 & 4.4 & $1.4 \pm 0.2$ & $2.1 \pm 0.3$ & $1.8 \pm 0.3$ & $1.7 \pm 0.3$ & $1.8 \mathrm{bc}$ \\
\hline & 0.0 & 8.8 & $1.7 \pm 0.3$ & $1.7 \pm 0.3$ & $2.2 \pm 0.3$ & $3.0 \pm 0.3$ & $2.1 \mathrm{ab}$ \\
\hline & \multicolumn{2}{|c|}{ Mean $^{\mathrm{w}}$} & $1.7 \mathrm{~b}$ & $1.9 \mathrm{ab}$ & $2.2 \mathrm{a}$ & $2.1 \mathrm{ab}$ & \\
\hline \multirow[t]{6}{*}{ Revanche } & 0.0 & 0.0 & 1.0 & 1.0 & 1.0 & 1.0 & \\
\hline & 4.4 & 0.0 & $1.4 \pm 0.1 \mathrm{~b}^{\mathrm{u}}$ & $2.9 \pm 0.4 \mathrm{ab}$ & $2.3 \pm 0.3 \mathrm{ab}$ & $3.5 \pm 0.8 \mathrm{a}$ & \\
\hline & 8.8 & 0.0 & $1.3 \pm 0.1 \mathrm{~b}$ & $1.7 \pm 0.3 \mathrm{~b}$ & $2.9 \pm 0.5 \mathrm{ab}$ & $2.9 \pm 0.3 \mathrm{ab}$ & \\
\hline & 0.0 & 4.4 & $2.0 \pm 0.3 \mathrm{ab}$ & $2.3 \pm 0.3 \mathrm{ab}$ & $2.8 \pm 0.3 \mathrm{ab}$ & $3.7 \pm 0.4 \mathrm{a}$ & \\
\hline & 0.0 & 8.8 & $3.0 \pm 0.4 \mathrm{ab}$ & $2.7 \pm 0.4 \mathrm{ab}$ & $2.2 \pm 0.2 \mathrm{ab}$ & $2.9 \pm 0.2 \mathrm{ab}$ & \\
\hline & \multicolumn{2}{|c|}{ Mean $^{\mathrm{w}}$} & $1.9 \mathrm{c}$ & $2.4 \mathrm{bc}$ & $2.6 \mathrm{~b}$ & $3.2 \mathrm{a}$ & \\
\hline \multirow[t]{6}{*}{ Alsace } & 0.0 & 0.0 & 1.0 & 1.0 & 1.0 & 1.0 & \\
\hline & 4.4 & 0.0 & $1.5 \pm 0.1$ & $2.2 \pm 0.3$ & $2.7 \pm 0.3$ & $2.8 \pm 0.3$ & $2.3 \mathrm{a}$ \\
\hline & 8.8 & 0.0 & $2.2 \pm 0.3$ & $2.3 \pm 0.4$ & $2.3 \pm 0.6$ & $2.2 \pm 0.3$ & $2.3 \mathrm{a}$ \\
\hline & 0.0 & 4.4 & $1.6 \pm 0.3$ & $1.3 \pm 0.3$ & $2.2 \pm 0.3$ & $1.5 \pm 0.2$ & $1.7 \mathrm{~b}$ \\
\hline & 0.0 & 8.8 & $1.6 \pm 0.2$ & $2.5 \pm 0.3$ & $3.0 \pm 0.3$ & $2.3 \pm 0.3$ & $2.3 \mathrm{a}$ \\
\hline & \multicolumn{2}{|c|}{ Mean $^{\mathrm{w}}$} & $1.7 \mathrm{c}$ & $2.1 \mathrm{bc}$ & $2.6 \mathrm{a}$ & $2.2 \mathrm{ab}$ & \\
\hline
\end{tabular}

${ }^{z}$ Data are means $\pm \mathrm{SE}$ of 12 replications after $45 \mathrm{~d}$ of culture.

${ }^{y}$ Analysis of variance for each cultivar was performed separately.

${ }^{x}$ Treatments without growth regulators were omitted from the analysis.

${ }^{\text {w}}$ Effect of culture medium. For each cultivar, values followed by the same letter are not significantly different according to the Tukey's test $(P \leq 0.05)$.

'Interaction of cytokinin type with cytokinin level in 'Splendens Giganteum' and 'Alsace'. For each cultivar, values followed by the same letter are not significantly different according to the Tukey's test $(P \leq 0.05)$.

"Interaction among culture medium, cytokinin type, and cytokinin level for 'Revanche'. Values followed by the same letter are not significantly different according to the Tukey's test $(P \leq 0.05)$.

$\mathrm{TDZ}=$ thidiazuron; $\mathrm{BA}=6$-benzylaminopurine; $\mathrm{BM}=$ basal medium; $\mathrm{BMN} / 2=\mathrm{BM}$ with the ammonium nitrate salt reduced to a half of its original concentration; $\mathrm{SHM}=$ Schenk and Hildebrandt medium; WPM = Woody Plant Medium.

The preferred protocol to propagate this cultivar includes WPM with $4.4 \mu \mathrm{M}$ TDZ that provides a mean of 2.8 shoots per explant with an average length of $12.7 \mathrm{~mm}$.

Results mentioned demonstrate that the three cultivars differed significantly with respect to multiplication rates with 'Revanche' producing the highest number of shoots per explant. The effect of genotype on in vitro propagation capability has been reported for many species, including ornamentals (Beruto et al., 2004; da Silva, 2004; Debnath, 2005; Hankoua et al., 2005; Phelan et al., 2009). Shoot yield also depended on media formulation. Thus, media with low ammonium concentrations (WPM and specially $\mathrm{SH}$ ) were superior to formulations based on MS medium (BM and BMN/2) as has been described for other woody species (McCown and Sellmer, 1987). A comparison between our results and those obtained previously by Jacquemont et al. (1992) seems to be difficult because these authors did not indicate the culture media and plant growth regulators used to promote axillary shoot development from cultured explants of the oleander cultivar Petit salmon.

\section{Adventitious shoot differentiation}

In the preliminary experiment, leaves on media without growth regulators produced no callus or adventitious buds and became senescent. The bud-forming capacity of the explants depended on the nutrient medium and cytokinin tested. Thus, the bud differen- tiation process occurred only on SHM supplemented with TDZ $(4.4$ or $8.8 \mu \mathrm{M})$ alone or in combination with IAA $(2.2 \mu \mathrm{M})$. In most cases, shoot formation occurred by callus (Fig. 1C). Occasionally, direct shoot organogenesis from intact surfaces and cut areas of explants was observed. The frequency of explants forming buds was relatively low (5\% to $10 \%)$ irrespective of explant source (seedling- or adult plant-derived shoots). Furthermore, TDZ-induced buds failed to elongate even when transferred to hormonefree SHM, a response previously reported in axillary bud proliferation experiments.

To determine culture conditions that provide production of well-developed shoots, in a new experiment, explants were first exposed to TDZ for 15 or $30 \mathrm{~d}$ and subsequently transferred to media containing combinations of BA/Kin/IAA (BKI) or BA/IAA (BI). The percentage of explants forming adventitious buds was age-dependent with leaves from juvenile origin responding better than those from adult material (average percentage of $20 \%$ versus $5 \%$ for juvenile and adult material, respectively). In addition, the subculture of explants to medium lacking TDZ but supplemented with BKI also favored bud elongation (Fig. 1C).

The highest frequency of explants forming buds $(40 \%)$ was obtained when leaf explants from juvenile material were cultured for $30 \mathrm{~d}$ in the presence of $8.8 \mu \mathrm{M} \mathrm{TDZ}$ and $2.2 \mu \mathrm{M}$ IAA and then transferred for $30 \mathrm{~d}$ to SHM with BKI 4.4/4.4/2.2 $\mu \mathrm{M}$. The organogenic response of leaves excised from adult cultures was cultivar-dependent with 'Alsace' and 'Splendens Giganteum' performing slightly better than 'Revanche' (average percentages of 6.7, 3.3, and 4.7 for 'Alsace', 'Revanche', and 'Splendens Giganteum', respectively). Culture conditions providing the best response (percent of organogenic explants) for each cultivar can be summarized as follows: for 'Splendens Giganteum', $30 \mathrm{~d}$ on induction medium and transfer to BI 4.4/0.4 $\mu \mathrm{M}(20 \%)$; for 'Alsace', $15 \mathrm{~d}$ on induction medium and transfer to BKI 2.2/2.2/0.4 $\mu \mathrm{M}(20 \%)$; and for 'Revanche', $30 \mathrm{~d}$ on induction medium and transfer to BKI 4.4/4.4/2.2 $\mu \mathrm{M}(8 \%)$. The mean number of well-developed shoots ( $5 \mathrm{~mm}$ or greater) formed per explant ranged from three to five. Neither exposure time to TDZ nor subculture media composition affected these results.

The effectiveness of TDZ in promoting adventitious shoot induction from oleander explants has also been demonstrated in a variety of plants (Gu and Zhang, 2005; Huettman and Preece, 1993; Murthy et al., 1998). Nevertheless, and as reported elsewhere (see Debnath, 2005), TDZ inhibited shoot elongation and therefore explants should be transferred to media with other cytokinins to produce well-developed shoots. We are unable to offer an explanation for the lack of adventitious shoot differentiation on WPM supplemented with TDZ, but the higher ammonium $\left(\mathrm{NH}_{4}\right)$ concentration of this medium compared with SHM (2.6 versus 5.0 $\mathrm{mEq}$ ) could be implicated. Similar results were reported for Juniperus oxycedrus (Gómez and Segura, 1995). In contrast, WPM has been used to induce organogenesis in some woody species (George et al., 1988).

\section{Rooting and acclimatization}

The percentage of rooted shoots was $99 \%$ either with hormone-free or IBA-containing $\mathrm{BM} / 2$ (Fig. 1D). The establishment of in vitrogrown plants in soil was easily achieved, and survival rates were $95 \%$ to $100 \%$. After their acclimatization, the plants were transferred to greenhouse conditions where they exhibited normal development, blossoming abundantly.

In conclusion, we have designed protocols for in vitro propagation by axillary shoot breaking of wild plants and commercial cultivars of Nerium oleander. These protocols combined with periods of culture on maintenance medium with or without BA can be used for storage and multiplication of selected oleander cultivars. Micropropagation allows higher multiplication rates than the propagation by cuttings, and rooting and acclimatization do not limit the efficient production of plants. This system could also be the basis for developing the meristem culture approach, which could be useful to obtain pathogen-free plants. We also report, for the first time, a protocol for regeneration of adventitious shoots from leaf explants of oleander that can be used to undertake transformation experiments. Nevertheless, further investigations are needed to improve the 
caulogenic potential, especially for adult plant-derived material, which will make oleander micropropagation more efficient and, consequently, reduce the cost of production.

\section{Literature Cited}

Adrover, M., A.L. Forss, G. Ramón, J. Vadell, G. Moya, and A.M. Taberner. 2008. Selection of woody species for wastewater enhancement and restoration of riparian woodlands. J. Environ. Biol. 29:357-361.

Bella, P., V. Catara, C. Guarino, and G. Cirvilleri. 2006. Evaluation of oleander accessions for resistance to Pseudomonas savastanoi pv. nerii. J. Plant Physiol. 88:273-278.

Beruto, M., L. Lanteri, and C. Portogallo. 2004. Micropropagation of tree peony (Paeonia suffruticosa). Plant Cell Tiss. Org. Cult. 79:249255.

da Silva, J.A.T. 2004. Ornamental chrysanthemums: Improvement by biotechnology. Plant Cell Tiss. Org. Cult. 79:1-18.

Debnath, S.C. 2005. A two-step procedure for adventitious shoot regeneration from in vitroderived lingonberry leaves: Shoot induction with TDZ and shoot elongation using zeatin. HortScience 40:189-192.

Fu, L.W., S.J. Zhang, N. Li, J.L. Wang, M. Zhao, J. Sakai, T. Hasegawa, T. Mitsui, T. Kataoka, S. Oka, M. Kiuchi, K. Hirose, and M. Ando. 2005. Three new triterpenes from Nerium oleander and biological activity of the isolated compounds. J. Nat. Prod. 68:198-206.

Gamborg, O.L., R.A. Miller, and K. Ojima. 1968. Nutrient requirements of suspension cultures of soybean root cells. Exp. Cell Res. 50:151-158.

George, E.F., D.J.M. Puttock, and H.J. George. 1988. Plant culture media. Vol. 2. Commentary and analysis. Exegetics Ltd., Edington, UK. p. 45-46.

Gómez, M.P. and J. Segura. 1995. In vitro control of adventitious bud differentiation by inorganic media components in leaves of mature Juniperus oxycedrus. In Vitro Cell. Dev. Biol. Plant 31: 179-182.

Gu, X.F. and J.R. Zhang. 2005. An efficient adventitious shoot regeneration system for Zhanhua winter jujube (Zizyphus jujuba Mill.) using leaf explants. Plant Cell Rep. 23:775-779.

Hankoua, B.B., S.Y.C. Ng, I. Fawole, J. PuontiKaerlas, M. Pillay, and A.G. Dixon. 2005. Regeneration of a wide range of African cassava genotypes via shoot organogenesis from cotyledons of maturing somatic embryos and conformity of the field-established regenerants. Plant Cell Tiss. Org. Cult. 82:221-231.
Hartmann, H.T., D.E. Kester, F.T. Davies, Jr., and R.L. Geneve. 2002. Hartmann and Kester's Plant Propagation. Principles and practices. 7th Ed. Prentice-Hall International, UK Ltd., London, UK.

Hoagland, D.R. and D.I. Arnon. 1950. The waterculture method for growing plants without soil. Calif. Agr. Exp. Stn. Circ. 347:32.

Huettman, C.A. and J.E. Preece. 1993. Thidiazuron: A potent cytokinin for woody plan tissue culture. Plant Cell Tiss. Org. Cult. 33: 105-119.

Huxley, A. (ed.). 1992. The new horticultural society dictionary of gardening. Vol. 3. MacMillan Publi. Co. Inc., London, UK.

Ibrahim, A.K., S. Khalifa, I. Khafagi, D. Youssef, I. Khan, and M. Mesbah. 2007. Stimulation of oleandrin production by combined Agrobacterium tumefaciens mediated transformation and fungal elicitation in Nerium oleander cell cultures. Enzyme Microb. Technol. 41:331336.

Ibrahim, A.K., S. Khalifa, I. Khafagi, D. Youssef, I. Khan, and M. Mesbah. 2009. Enhancement of oleandrin production in suspension cultures of Nerium oleander by combined optimization of medium composition and substrate feeding. Plant Biosyst. 143:97-103.

Jacquemont, R., J.P. Onesto, P. Poupet, and R. Franco. 1992. Valorisation par la multiplication in vitro d'un caractere naturel de nanisme: Cas du laurier-rose (Nerium oleander). Acta Hort. 320:133-139.

Lloyd, G.B. and B.H. McCown. 1980. Commerciallyfeasible micropropagation of mountain laurel, Kalmia latifolia, by use of shoot tip culture. Proc. Int. Plant Propagators Soc. 30:421-426.

Mackay, W.A., M.A. Arnold, and J.M. Parsons. 2005. Nerium oleander L. 'cranberry cooler', 'grenadine glace', 'pink lemonade', 'peppermint parfait', 'raspberry sherbet', and 'petite peaches and cream'. HortScience 40:265268.

Manna, S.K., N.K. Sah, R.A. Newman, A. Cisneros, and B.B. Aggarwal. 2000. Oleandrin suppresses activation of nuclear transcription factor NF-kB activator protein-1, and c-June NH2-terminal kinase. Cancer Res. 60:38383847.

McCown, B.H. and J.C. Sellmer. 1987. General media and vessels suitable for woody plant culture, p. 4-16. In: Bonga, J.M. and D.J. Durzan (eds.). Cell and tissue culture in forestry. Vol. 1. Martinus Nijhoff Publishers, Dordrecht, The Netherlands.

Mize, C., J.K. Kenneth, and M.E. Compton. 1999. Statistical consideration for in vitro research:
II-Data to presentation. In Vitro Cell. Dev. Biol. Plant 35:122-126.

Murashige, T. and F. Skoog. 1962. A revised medium for rapid growth and bioassays with tobacco tissue culture. Physiol. Plant. 15:473497.

Murthy, B.N.S., S.J. Murch, and P.K. Saxena. 1998. Thidiazuron: A potent regulator of in vitro plant morphogenesis. In Vitro Cell. Dev. Biol. Plant 34:267-275.

Niu, G.H., D.S. Rodriguez, and W. Mackay. 2008. Growth and physiological responses to drought stress in four oleander clones. J. Amer. Soc. Hort. Sci. 133:188-196.

Ozden-Tokatli, Y., A. De Carlo, F. Gumusel, S. Pignatelli, and M. Lambardi. 2008. Development of encapsulation techniques for the production and conservation of synthetic seeds in ornamental plants. Prop. Ornam. Plants 8:1722.

Pal, D., S.K. Gupta, and C. Singh. 1990. Organogenesis and plant regeneration in leaf callus culture of Nerium oleander L. Ad. Plant Sci. 3:61-65.

Paper, D.H. and G. Franz. 1993. Nerium spp.: In vitro culture and the production of secondary metabolites, p. 233-248. In: Bajaj, Y.P.S. (ed.). Biotechnology in agriculture and forestry, medicinal and aromatic plants IV. Vol. 21. Springer-Verlag, Berlin, Germany.

Phelan, S., A. Hunter, and G.C. Douglas. 2009. Effect of explants source on shoot proliferation and adventitious regeneration in 10 Buddleia cultivars. Sci. Hort. 120:518-524.

Profumo, P., A.M. Gastado, and C.U. Riboldi. 1993. Formation of cardiac glycosides in calli from leaf explants of Nerium oleander L. Plant Med. Phytother. 26:346-349.

Santos, I., I. Guimaraes, and R. Salema. 1994. Somatic embryogenesis and plant regeneration of Nerium oleander. Plant Cell Tiss. Org. Cult. 37:83-86.

Schenk, R.V. and A.L. Hildebrandt. 1972. Medium and techniques for induction and growth of monocotyledonous and dicotyledonous plant cell cultures. Can. J. Bot. 50:199-204.

Tukey, J.W. 1953. Some selected quick and easy methods of statistical analysis. Trans. N. Y. Acad. Sci. Ser. II 16:88-97.

Zhao, M., L.M. Bai, L.Y. Wang, A. Toki, T. Hasegawa, M. Kikuchi, M. Abe, J. Sakai, R. Hasegawa, Y.H. Bai, T. Mitsui, H. Ogura, T. Kataoka, S. Oka, H. Sushima, M. Kiuchi, K. Kirose, A. Tomida, T. Tsuruo, and M. Ando. 2007. Bioactive cardenolides from the stems and twigs of Nerium oleander. J. Nat. Prod. 701:1098-1103. 